Dušan Rajić ${ }^{1}$, Negovan Ivanković ${ }^{2 *}$

${ }^{1}$ University of Belgrade, Innovation Center, Faculty of Technology and Metallurgy, Belgrade, Serbia, ${ }^{2}$ University of Defence in Belgrade, Military Academy, Belgrade, Serbia
Scientific paper

ISSN 0351-9465, E-ISSN 2466-2585

UDC: $614.894 .2: 66-911.38+620.3$

doi:10.5937/zasmat1904360R

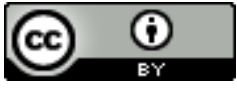

Zastita Materijala 60 (4)

$360-368$ (2019)

\title{
Contributions of impregnated silver nanoparticles to ideality increase of filtration material in human respiratory protection
}

\begin{abstract}
A technical contradiction arises when within a system one parameter improves thus automatically causing another one to worsen. In a situation like this, instead of a usual acceptance of compromise which leads to optimization of a solution for a newly founded problem, in inventology we implement the process of idealisation. The experimental part of this study comprises comparative examination of $\mathrm{NaCl}$ aerosol leakage, as a simulator of biological agents, into the epidemiological anti-microbe masks EM1 and EM2, with the aim of determining physiological suitability of EM1 and EM2 and the resistance that arises when inhaling $\mathrm{NaCl}$ aerosol was measured at the flows of $95 \mathrm{dm}^{3} / \mathrm{min}$. It was experimentally proved that impregnation of silver nanoparticles onto the inner filtrating layer of EM2 contributes to the increase of its efficiency, and mathematical modelling helped calculate the realistic increase of this means.
\end{abstract}

Keywords: idealisation, mathematical modelling, protective half-masks.

\section{INTRODUCTION}

Inventology starts from the fact that in the technical-technological problem one should not look for an optimum but an ideal final solution (IFS) [1]. Once an ideal system is achieved, then its dimensions and energy capacity strive towards zero, and the ability to execute the main useful function (MUF) is not diminished. Idealism always reflects on the maximum utilisation of existing system resources. The cheaper these resources, the greater the chance of using them, the system will be more ideal. The ideality formula was first proposed by Altshuler [2]:

$$
I=\Sigma F /(\Sigma C+\Sigma D)
$$

where is:

$I$ - an ideal or an IFS system;

$\Sigma F$ - total system functionalities (benefits);

$\Sigma C$ - total system damage;

$\Sigma D$ - total maintenance costs of the system.

\footnotetext{
${ }^{*}$ Corresponding author. Negovan Ivanković

E-mail: negovan.ivankovic@gmail.com

Paper received: 29. 05. 2019.

Paper accepted: 25. 07. 2019.

Paper is available on the website:

www.idk.org.rs/journal
}

However, due to increased demands for objectivity and validity of the methodology of estimating the achieved ideality degree in engineering systems, there are efforts to show formula (1) with a more precise quantitative meaning [2]. The fact that the real system is asymptotically approaching the ideal system by removing contradictions, using all available resources, minimizing components, using new physical, chemical and geometric phenomena and effects without increasing the harmful functions [1], must be considered.

Inventology is based on Theory of Inventive Inventory Theory (Rus. abr. TRIZ), which essentially identifies, emphasises and eliminates technical contradictions (TC)and physical contradictions in the system (S), and does not tend to create a compromise through optimisation of parameters. The term TC is the key to the TRIZ concept. One TC represents two contradictory features of the system. Improving one part or one feature of a system (for example, increasing the protection factor in respiratory protection) automatically aggravates some of their other characteristics (for example, breathing resistence increases, which reduces the comfort of wearing that agent in operational use). In accordance with TRIZ, the problem is solved only if the TC is 
identified and eliminated. Demonstration of the application of the $40 \mathrm{TRIZ}$ principles, as its most popular tool, is explained on numerous examples of technical-technological $[1,3]$ and ecological products [2,4]. With 76 Innovation Standards, as the following essential TRIZ tool, each class of standards is sub-divided into sub-classes and subgroups [1-4]. In order to solve technicaltechnological problems using TRIZ standards, it is first necessary to determine which class belongs to the given problem, then to which sub-class and the group it can be classified. Special attention should be given to the fifth class of standards. It is applied when there are complications in the search for substances or fields that are missing. This class increases the degree of ideality of the system on which it is working, because it is focused on the maximum use of resources, both substances and fields that exist in the given system [5].

In this study, the contribution of the nano layer of silver impregnated in the filter of the epidemiological hemisphere (EM2) to the increase of ideality in the process of its respiratory protection was examined, compared to the model of the epidemiological polymasic antimicrobial (EM1) model that does not have in its structure the nano material. In this respect, a comparative study of the protection efficiency was performed by measuring the leakage of aerosols through the filtering medium, in artificially simulated conditions of contamination of the environment by biological agents (BAg), while the physiological suitability test of EM was made by measuring the resistance in inhalation.

\subsection{The law of ideality increment}

According to TRIZ, the Law of Ideality Increment represents one of eleven laws of engineering system evolution [1].

In reality there is no ideal system. In every useful system some harmful effects appear. This very harmful system is always ideal, because no one creates it, it organises itself instead [1]. If the formula (1) expends it is possible to obtain a relationship of so-called ponder masses [6]:

$$
I=\left(k_{1} F_{1}+k_{2} F_{2}+\ldots+k_{n} F_{n}\right) /\left[\left(I_{1} C_{1}+I_{2} C_{2}+\ldots+I_{n} C_{n}\right)+\left(m_{1} D_{1}+m_{2} D_{2}+\ldots+m_{n} C_{n}\right)\right]
$$

where: I - IFS; k, I, m - coefficients representing the significance of useful system functions, costs and harmful functions of the system.

In this form the formula is still non-functional, because the terms have different units (e.g., the protective power at EM cannot be combined with its mass). The problem can be solved by switching to normalised parameters without units, but in this case the formula has at least two problems. These are the problems of mathematical and subjective linearity. Namely, if it doubles the functionality of the system, it does not mean that the ideality of the engineering system will increase [6]:

$$
I_{1}=F /(C+D), I_{2}=2 F /(C+D)=>I_{2}=2 I_{1}
$$

According to formula (3), many of the small advantages of a system can compensate for one major (limiting) defect, such as, for example, mandatory minimum value of the protection factor prescribed by the standard. Accordingly, from the point of view of the mathematical linearity, formula (3) should be re-examined. It should also be reconsidered from the point of view of subjective linearity, as technology and technology evolve to meet the needs of users. For this reason, the user is the one who needs to decide whether and how much the engineering system has been given is satisfactory. For example, if a person is found in a very dangerous life situation in which an accidental release of BAg can occur, he/she will probably be without much thought to use the first EM at hand, ignoring the possibility of his protective power in relative to the exempt BAg. However, if the same person is in a normal life situation, which does not endanger him, then he will choose among available options the most adequate EM which is guaranteed to protect against a particular type of BAg. It means that his/her answer is different in two different situations, despite what formula (3) claims. Improving any engineering system means improving one or more of its main parameters. Displaying the absolute value of parameter $P$ cannot show whether the selection of this parameter is good or bad, whether it is a lot or too little, etc. Therefore, the parameter $\mathrm{P}$ for an interval should be normalised [6]:

$$
P n=\frac{P-P \min }{P \max -P \min }
$$

where $P_{n}-$ normalised parameter for interval $P_{\text {min }}$, $P_{\max }$;

$P_{\min }, P_{\max }-$ minimal allowed and maximum necessary parameter values

$P_{\min }$ and $P_{\max }$ have a real physical meaning. Their values are usually prescribed by appropriate standards and in this case, they are binding by law. 
$P_{\min }$ is the minimum allowed value of the parameter, below which the user will not accept the engineering system under any circumstances. For example, if users who are continuously exposed to $\mathrm{BAg}$ are offered a single-use EM, which can protect the user for half an hour, and only from a particular type of BAg, most probably nobody will buy it regardless of its advantages (low price, comfort, availability, etc.). If EM is good enough for all-day protection, it will most likely be purchased. Therefore, there is a minimum protection time between these two values, under which no one will consider purchasing such an EM, and above it will consider possible purchase. Similarly, Pmax is the maximum necessary parameter value so that its further exceedance will not be essential to the user, and such an increase will not necessarily be considered an improvement. For example, if the standard provides a $99 \%$ protection factor for EM, which guarantees respiratory protection of a very high level by the user, and the measurement found that it is $99.99 \%$ in real terms, it is unlikely that the user will be delighted by it. Therefore, there is always a certain limit beyond which further improvements are meaningless. Since the quality of the engineering system is determined by several parameters of different meaning for the user, it is necessary to introduce weight coefficients $(K)[6]$ :

$$
P n=\left(\frac{P-P \min }{P \max -P \min }\right) K
$$

where $\mathrm{K}$ - ponder coefficient, $0<\mathrm{K}<1$

As already mentioned, when evaluating system ideality, account is taken of not so much the value of the parameters that have been achieved, but the user's response to their improvement. This answer also depends on another factor called the degree of saturation of the market or the degree of availability of this parameter on the market. In the small-scale market, even small improvements will be of interest, while the user in a highly saturated market may be uninterested even when offered a significant improvement in the parameters of the engineering system. Therefore, for one parameter the formula should look like the following [6]:

$$
S=\frac{\left(\frac{P-P \min }{P \max -P \min }\right) K L}{1}-L
$$

where $S$ - user' satisfaction with the parameter value $P$;

$$
\mathrm{L}-\text { coefficient of market saturation } 0<\mathrm{L}<1
$$

If the measuring units are such that the improvement of the system implies a decrease in the parameter value (for example, in EM, the increase in total resistance in inhalation is an unwanted effect), then the formula looks like this [6]:

$$
S=\frac{\left(\frac{P \max -P}{P \max -P \min }\right) K L}{1}-L
$$

$P_{\min }$ and $P_{\max }$ are the minimum and maximum allowed parameter values (the improvement limit is $P_{\min }$, not $\left.P_{\max }\right)$. For low values of $K$ and $L$, which means that they represent an insignificant parameter in the unsaturated market, user satisfaction is easy to achieve. It is enough to achieve quality that is slightly above the permissible minimum. In the limited case of a market without competition (monopoly), where $L=0$ for any $P>P_{\min }$, satisfaction is $S=1$, because the user will accept anything that is available for sale. A similar result will be obtained for $K=0$, which means that this parameter is so irrelevant for the user that it does not affect purchasing decisions, which means that it is not IFS. Conversely, if the parameter is significant and the market is quite saturated, even a significant improvement in the parameter will not excite the user. Interestingly, for some average values of $\mathrm{K}$ and $\mathrm{L}$, the user corresponds to the linear dependence on the parameter, which means that it is doubly twice as good and twice as good. In other words, the subjective linearity of the formula for calculating the ideal does not always lead to errors. However, this works only in a small number of cases. Similarly, mathematical linearity is not a problem for relatively small changes in parameter values. In these cases, it makes one parameter worse, whereby it can really be compensated by improving several other parameters. Another limiting case is an excessively high value for $P_{\max }$. This means that no improvement of the parameter can satisfy the user, because compared to the infinite value, any final number does not differ from zero.

Now, the overall characteristics of the system, which can be called practical IFS [6], can be calculated:

$$
I F S=\left(\prod_{i=1}^{n}[S i) \rrbracket_{1 / n}=(S 1 S 2 \ldots S n)^{1 / n}\right.
$$

where IFS- practical value of the ideal final solution; $\mathrm{Si}$ - user's satisfaction with the parameter value $\mathrm{Pi} ; \mathrm{n}$ - number of parameters.

Also, the relative harmful $\mathrm{Ri}$ regime can be calculated as a "negative contribution" of every parameter to the practical value of the engineering system [6]: 


$$
R i=\frac{1-S i}{\sum_{i=1}^{n}(1-S i)}
$$

\section{EXPERIMENTAL PART}

All samples of tested EM are the product of company "9th September" from Gornji Milanovac, Serbia. EM are used to protect the respiratory organs of users and persons that are located in the vicinity of BAg contamination, which is transferred to the ground. They consist of three layers made of non-woven textile or polypropylene and one filter layer, which in the case of EM2 is impregnated with silver nano-particles. Worldwide manufacturers of respiratory protection devices, in the form of impregnated nanoparticles, use silver because of its pronounced antibacterial properties [7-9]. Unlike EM1 that have air vents 5 to $50 \mu \mathrm{m}$ in size, EM2 nano-masks have 1-2 $\mathrm{nm}$ openings on the silver coating layer.

It can be graphically presented with the help of Figure 1.

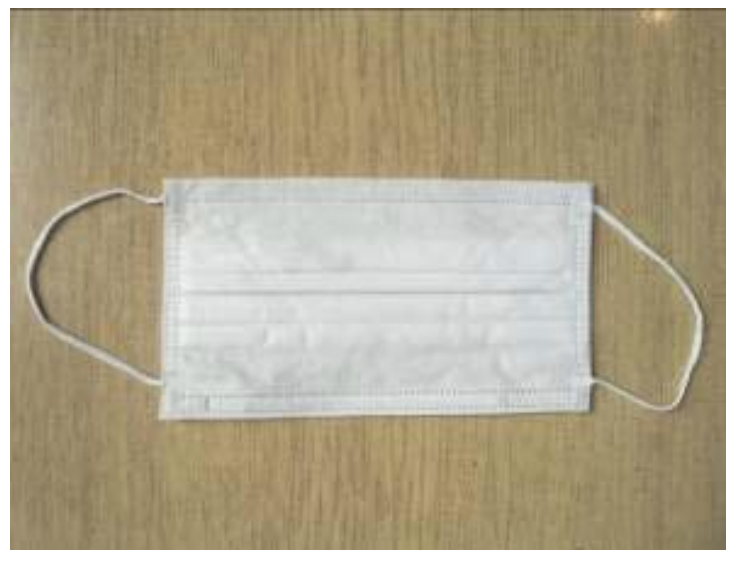

(a)

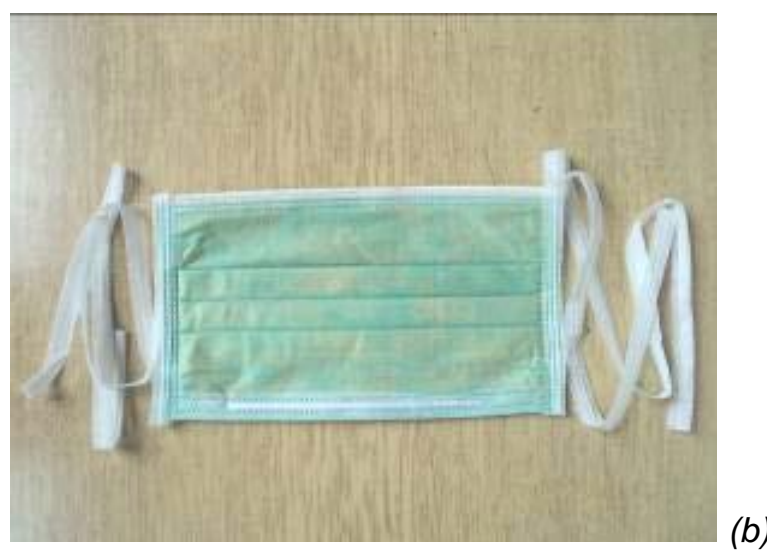

Figure 1. Samples of the epidemiological antimicrobe masks: (a) model EM1, (b) model EM2 (with silver nano-particles)

Slika 1. Uzorci epidemioloških anti-mikrobnih maski: (a) model EM1, (b) model EM2 (sa nano česticama srebra)
In the test of EM samples, the method for testing with $\mathrm{NaCl}$ was defined in the standard [10]. This method is based on the principle of leakage of $\mathrm{NaCl}$ aerosol through a filtering medium, whereby the concentration of this aerosol is measured before and after the test sample by the flame photometry method. Precise determinations are possible in the field of penetration from $0.0001 \%$ to $100 \%$. With $1 \%$ aqueous $\mathrm{NaCl}$ solution, Collison (the manufacturer of $\mathrm{BGI}$, USA) produced a polydispersion solid aerosol concentration $\mathrm{CO}=8$ $\mathrm{mg} / \mathrm{m}^{3}$ with the following characteristics: particle diameter $\mathrm{dp}=0.02-2.0 \mu \mathrm{m}$, median particles per mass $\mathrm{MMD}=0.60 \mu \mathrm{m}$, median particle by NMD = $0.03 \mu \mathrm{m}$, geometric deviation $\sigma \mathrm{g}=2.53$. The geometric particle distribution is determined by an electrical particle analyser EAA-3030 (manufacturer of TSI, USA). The test was carried out in the test chamber at a flow rate of 95 $\mathrm{dm} 3 / \mathrm{min}$, and the test aerosol concentration was measured before and after the filter tested using a flame photometer Type 1100 (manufacturer Moores, Wallisdown LTD., UK).

A test chamber was used to test the effect of the flow of aerosol on the EM filtration efficiency. The test was carried out by connecting the EM to the filtering medium, then the aerosol probe was connected, and the test aerosol supply to the test chamber was switched on. Using the flow meter, the desired flow rate of the test aerosol was set to $95 \mathrm{dm}^{3} / \mathrm{min}$, so the test aerosol continuously flowed through the EM. The aerosol concentration was measured before and after the test sample using a flame photometer. The leakage was measured over $30 \mathrm{~min}$ every $5 \mathrm{~min}$ from the start of the test, as the average response of the instrument for a time interval of $30 \pm 3 \mathrm{~s}$, and the read data was recorded. At the same time, the gauge also measured the resistance of the filtering medium through the flow of aerosols and the data is recorded. The manometer was connected to the space below the medium in the dispenser of the filter medium with one copy and the other open to the atmosphere.

The results obtained by the experimental tests were grouped according to the series according to the performed tests. The basic statistical parameters series of results were obtained by their processing using the statistical software package IBM SPSS Statistics Data Editor, version 20. The statistical significance in the processing of the results was defined at a probability level of 0.05 . 


\section{RESULTS AND DISCUSSION}

\subsection{Testing leaking through the filtrating medium}

Leakage values $(P)$ through the filtration halfmasks, obtained by experimental tests of each model of said media at the flow rate of the test aerosol of $95 \mathrm{dm}^{3} / \mathrm{min}$, were grouped according to the series in the test procedure and the basic statistical parameters were given in Table 1.

Table 1. Statistical parameters of the leakage result series through EM at the flow rate of the test aerosol $\mathrm{NaCl}$ of $95 \mathrm{dm}^{3} / \mathrm{min}$

Tabela 1. Statistički parametri serija rezultata propuštanja kroz EM pri protoku ispitnog aerosola $\mathrm{NaCl}$ od $95 \mathrm{dm}^{3} / \mathrm{min}$

\begin{tabular}{|c|c|c|c|c|c|c|}
\hline $\begin{array}{c}\text { Tested } \\
\text { model }\end{array}$ & $\mathrm{N}$ & $\overline{\mathrm{X}}$ & $\mathrm{SD}$ & Standard error & $\begin{array}{c}\mathrm{P}_{\min } \\
(\%)\end{array}$ & $\begin{array}{c}\mathrm{P}_{\max } \\
(\%)\end{array}$ \\
\hline EM1 & 9 & 0,85693 & 0,01017 & 0,0033885 & 0,8403 & 0,8696 \\
\hline EM2 & 9 & 0,91652 & 0,01008 & 0,0033614 & 0,9019 & 0,9283 \\
\hline
\end{tabular}

According to the criteria defined in the standard [11], it is envisaged that for the leakage test with the $\mathrm{NaCl}$ test agent at a flow rate of $95 \mathrm{dm}^{3} / \mathrm{min}$ the test value of each sample EM should not exceed $20 \%$ for the FFP1 class, $6 \%$ for the FFP2 class and $1 \%$ for the FFP3 class of this type of protective agent. In Tab. 1 it can be seen that in relation to the standard defined value of $1 \%$, the leakage values through the filtering material in the test samples of the model EM1 and EM2 are slightly less. Accordingly, the samples EM1 and EM2 belong to the highest FFP3 class.

The arithmetic average leakage values through the filtering medium at $95 \mathrm{dm}^{3} / \mathrm{min}$ of the test aerosol in both EM models are below the limit of the leakage criteria for this type of protective agent [8], so that the tested models fall into the most efficient FFP3 class. In addition, standard deviations of leakage values within a series of results in both models of these agents are also small (EM1 - 0,01017; EM2 - 0,01008).

According to the above, it can be observed that, in accordance with the EM criteria, in both models high quality filtering materials are incorporated. Testing the normal statistical distribution of results obtained by experimental tests showed that the values of the test were subject to normal statistical distribution in both tested models of the said protective agents. The results of testing the normal statistical distribution of results with a Shapiro-Wilk test with a statistical significance at a probability level of 0.05 showed that the statistical significance of Sig. for EM1
0.489, and for EM2 0.207. Accordingly, the test values of both models with a normal distribution of results were further tested with the One-Way ANOVA test. It is suggested that the efficiency of filtering these materials depends directly on the quality of the embedded filtering materials, i.e. their structural properties. Based on the obtained results, it can be concluded that EM2 models incorporate filtering materials that possess a layer of impregnated silver nano-particles with a better quality than the EM1 model.

\subsection{Physiological suitability test}

The values of the inhalation resistance (p) EM, obtained by testing each model of the above mentioned devices at the air flow rate of 95 $\mathrm{dm}^{3} / \mathrm{min}$, are grouped according to the series in the test procedure and shown in Table 2.

Table 2. Statistical parameters of the series of results of resistance during inhalation of EM at the flow of air of $95 \mathrm{dm} / \mathrm{min}$

Tabela 2. Statistički parametri serija rezultata vrednosti otpora pri udisanju EM pri protoku vazduha od $95 \mathrm{dm}^{3} / \mathrm{min}$

\begin{tabular}{|c|c|c|c|c|c|}
\hline $\begin{array}{c}\text { Tested } \\
\text { model }\end{array}$ & $\mathrm{N}$ & $\begin{array}{c}\overline{\mathrm{X}} \\
(\mathrm{Pa})\end{array}$ & $\mathrm{SD}$ & $\begin{array}{c}\text { Standard } \\
\text { error }\end{array}$ & $\begin{array}{c}\mathrm{P}_{\min }-\mathrm{P}_{\max } \\
(\mathrm{Pa})\end{array}$ \\
\hline EM1 & 9 & 142,78 & 2,64 & 0,878 & $140-145$ \\
\hline EM2 & 9 & 128,89 & 4,17 & 1,389 & $125-135$ \\
\hline
\end{tabular}

According to the criterion defined in the standard [11], the resistance value of inhalation of each sample EM at $95 \mathrm{dm}^{3} /$ min must not exceed $210 \mathrm{~Pa}$ for the FFP1 class, $240 \mathrm{~Pa}$ for the FFP2 class and $300 \mathrm{~Pa}$ for the FFP3 class of this type of device.

From Tab. 2 it can be seen that in the air flow rate of $95 \mathrm{dm}^{3} / \mathrm{min}$, the resistance values for inhalation are less than the defined $300 \mathrm{~Pa}$ criterion in all test samples EM1 and EM2. According to the presented, all EM samples fully meet the set criteria.

Testing of the normal statistical distribution of results obtained by experimental tests at 95 $\mathrm{dm}^{3} / \mathrm{min}$ airflow showed that the values of the test are not subject to normal statistical distribution in the EM1 and EM2 models. The results of testing the existence of statistically significant differences between the series of results obtained from 95 $\mathrm{dm}^{3} / \min$ (at a probability level of 0.05 ) show that there is no statistically significant difference between the EM1 and EM2 series resistance results indicating that their built-in filtering materials has similar structural characteristics. However, when it comes to the fact that EM1 and EM2 are 
four-layer filtering polymers, it can be concluded that there is actually a big difference between the structural characteristics of the embedded filtering materials. The less pronounced differences in resistance values in the EM1 and EM2 models can be explained by the fact that by increasing the air flow velocity, there is a greater support due to higher flow through a small filtering surface, causing the fibers of the filtering material to collapse, causing a decrease in the pore between the fibers and the relative increase active filtering surfaces in relation to the volume of air flow, resulting in increased resistance. From this it can be concluded that this phenomenon is more pronounced with filtering materials with a lower density of packaging, that is, the manifestation of the influence of this phenomenon depends primarily on the structural characteristics of the filtering materials $[12,13]$.

The dynamics of aerosol filtering by filtering media is the result of changes that occur in the filtering material itself, or a change in its structure during exploitation. These changes are most commonly due to the precipitation of particles on the fibers of the filtering material, when the separated particles are not distributed properly over the surface of the fibers, but form chains, thereby increasing the obstruction thickness (fiber
+ precipitated particles) and reducing porosity. Due to this process, the efficiency of the filtering medium increases with a slight increase in resistance. The longer the filtering process is, or the higher the concentration of particles in the aerodispersion system, the faster the formation of a more homogeneous layer of particles, which, depending on the size, affects the greater or lesser increase in the resistance of the aerosol flow. If the aerosol and the flow of constant characteristics are, ideally, the efficiency of the filtering and resistance changes are directly proportional to the filtering time.

According to this setting, the quality characteristics of a particular filtering material can be determined by testing the aerosol filtration dynamics by filtering media, i.e. by testing the filtration efficiency at different flows, and by simultaneously testing the filtering efficiency and changing the resistance of the filtering material depending on the filtering time at different flows.

\subsection{Calculating the ideality of the filtering half- masks}

From the point of view of the practical value of devices, it is necessary to determine the value of IFS in EM1 and EM2 (Table 3).

Table 3. The achieved degree of ideality in the construction of EM1 and EM2

Tabela 3. Postignuti stepen idealnosti u konstrukciji EM1 i EM2

\begin{tabular}{|c|c|c|c|c|}
\hline & $\begin{array}{c}\text { Leakage through the } \\
\text { filtering medium EM1/EM2 }\end{array}$ & $\begin{array}{c}\text { Inhalation resistence (Pa) at the } \\
\text { flow of } 95 \mathrm{dm}^{3} / \mathrm{min}, \mathrm{EM} 1 / \mathrm{EM} 2\end{array}$ & $\begin{array}{c}\text { Comfort (points), } \\
\text { EM1/EM2 }\end{array}$ & $\begin{array}{c}\text { IFS (\%) } \\
\text { EM1/EM2 }\end{array}$ \\
\hline $\mathrm{P}_{\min }-\mathrm{P}_{\max }$ & $0.8403-0.9283$ & $125-145$ & $1-10$ & \\
\hline $\mathrm{P}$ & $0.85693 / 0.91652$ & $143 / 129$ & $8 / 9$ & $-/ 47.8$ \\
\hline $\mathrm{K}$ & 0.9 & 0.9 & 0.8 & \\
\hline $\mathrm{L}$ & 0.8 & 0.9 & $45.2 / 68.6$ & \\
\hline $\mathrm{S}, \%$ & $25 / 59.6$ & $7.9 \times 10^{-1} / 16.4$ & $23.9 / 20.2$ & \\
\hline $\mathrm{R}, \%$ & $32.6 / 26$ & $43.5 / 53.8$ & & \\
\hline
\end{tabular}

From the standpoint of ideality, it has been found that for both types of EM, the main problem is inhalation resistance at a flow rate of $95 \mathrm{dm}^{3} / \mathrm{min}$. For EM1, it is almost $0\left(\mathrm{~S} 2=7.9 \times 10^{-7}\right)$, which indicates that the necessary condition is not fulfilled, which allows calculation of IFS. This necessary condition is that all tested parameters of the agent must be greater than 0 . On the other hand, for EM2 IFS $=47.8 \%$. Since this is a quantitative calculation, this means that a real budget is enabled. This is important because all the necessary values are approximately familiar: the choice of parameters $\mathrm{Pi}$, their current values, the relative importance of $\mathrm{Ki}$, and the possible interval values $\left(P_{\min }, P_{\max }\right)$ reflect knowledge of user's needs and saturation coefficients on the market, while $\mathrm{Li}$ - available knowledge on market offer of the product. This information is essential for the implementation of consulting or project services. This analysis considers mathematical non-linearity. In addition, it also considers subjective non-linearity over a parameter interval, ponder, and a market saturation coefficient. It is possible to identify prohibited variants of modification engineering of devices where the improvement of one of the parameters, even if it is very significant, makes at least one IFS parameter equal to zero, which makes this modification useless. It also allows the identification of unreasonable variants of modification leading to the passage of some 
parameters to a zone that represents a meaningless resource consumption, as this does not increase IFS.

The practical value of IFS is the dimensionless value in the range 0 to 1 , and it can also be displayed as a percentage, and used to compare all engineering systems, including those with different set of parameters. Idealisation of the first type occurs when the mass (m), dimension (d), and the energy capacity $(E)$ of the system tend to be zero, and MUF or the sum of all executable functions remains unchanged [14]:

$$
\operatorname{IFS}(S 1)=\lim _{\substack{m, d, E \rightarrow 0 \\ n=\text { const. }}} \operatorname{MUFn}(m, d, E)
$$

The other type of idealisation occurs when MUF or the number of executable functions increases, and mass, dimensions and energy capacity remain unchanged or grow disproportionately low in relation to MUF growth [14]:

$$
\operatorname{IFS}(S 2)=\lim _{\substack{m, d, E=\text { const. } \\ n \rightarrow \infty}} \operatorname{MUFn}(m, d, E)
$$

The general aspect of the idealisation of the engineering system consists of both processes: reducing $\mathrm{m}, \mathrm{d}, \mathrm{E}$, and increasing MUF or all the useful functions of the system [11]:

$$
\operatorname{IFS}(S)=\lim _{\substack{m, d, E=0 \\ n \rightarrow \infty}} \operatorname{MUFn}(m, d, E)
$$

If the development of any engineering system is monitored, as well as respiratory protection devices, over time, then, as a rule, development begins with the process of idealisiation of the secondary type, sometimes called - expansion of the system. At this stage, the number of system functions increases, and accordingly, the subsystems that realise additional functions appear in the system (for example, EM introduces a filter layer impregnated with silver nano-particles as a sub-system that improves antibacterial protection, raises comfort and overall protection efficiency). The improvement process of EM described above through the installation of new sub-systems illustrates the process of system expansion in an illustrative way. Thereafter, the number of functions performed by the system is stabilised and the process of idealisation of the primary type, called reduction or transformation, is initially initiated in it (for example, the number of EM layers can be reduced). Often, both processes of idealisation occur simultaneously, and at the system level, the process of expansion begins, i.e. the idealisation of another type, and at the sub-system level - the process of reduction or transformation, i.e. primary type idealisation [6]. The process of expansion of the system engineering always starts from the substance, in the concrete case by introducing into the system of silver nano-particles of silver. It is precisely at the substance level that the effects of those factors that prevent the increase of MUF are strongly demonstrated. Then the phase of transformation of the system occurs. Therefore, the process of idealisation of an engineering system can be described by the formula [14]:

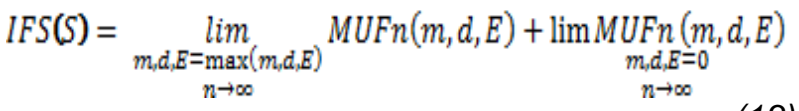

From formula (13) it can be seen that the ideality (IFS) is achieved first through the expansion of the engineering system, and then through its transformation, for example, transition from a mono-system to bi-, poly- and then back to the mono-system, but with improved or completely new functional characteristics. Formula (13) is a limiting case where all $\mathrm{Si}=1 \Rightarrow \mathrm{IFS}=1$. This means that all functional parameters have reached their best values, and the costs are reduced to insignificant levels. Such a system is perfectly suited to the "approximating ideal system". It functions only where it is needed, when necessary and in the way, it is needed. In this way, the system does not have to completely disappear as long as it retains the ability to perform its own functions.

\section{CONCLUSION}

Protection of respiratory organs against BAg is being realised by wearing different types of EM. Since the effects of protection and physiological suitability are the key parameters that these agents should satisfy, their reliable assessment was carried out by tests of leakage of $\mathrm{NaCl}$ aerosol as a simulator of BAg. Aerosol leak test to the interior revealed that both models EM1 and EM2 meet the prescribed criteria for the class P3 half-masks. This shows that both EM materials are of superior quality. Based on the obtained test results, the embedded filtering material in the EM2 model has a slightly lower packing density and slightly higher charging capacity than the EM1 model. This can be explained by the presence of a layer of basic filter material with impregnated silver nanoparticles that have positive polarity, so that all the reversely charged particles get encapsulated in their their 
potential pit. This results in a higher activity of the basic filtering material. This is confirmed by the experiment result, where after a long time exposure to the test aerosol, the model EM2 provided less leakage with less resistance than the EM1 model.

Based on the subjective observations of the respondents, it was concluded that the EM2 has a better fit on the user's face and provides greater comfort for wearing. In this sense, EM2 is an improvement compared to the protective half-mask of previous generations of EM1 model.

Since EM1, unlike EM2, did not satisfy the necessary criteria for the calculation of ideality for all individual parameters, IFS was not calculated. In EM2 it is necessary to determine its position on the evolutionary development line. In this respect, it is necessary to objectively evaluate the obtained technical solution of the specific engineering problem, and also to make several modifications of this solution towards the effect of the laws of technical evolution. It is also necessary to forecast further development of this resource and more precisely to formulate TCs that prevent it. In this sense, further structural improvements of EM1 and EM2 should be aimed at reducing resistance during inhalation and increasing filter efficiency. This can be achieved by installing better quality materials from which the EM layers are made, in order to achieve a lower packing density and increase the charging capacity, i.e. less leakage of the contaminant and less resistance to inhalation of air. This would also increase the comfort of wearing this EM.

The formula for calculating the degree of ideality of the engineering system as a measure of their efficiency can be recommended for wider use in the following situations: to plan and evaluate the outcomes of innovation from the point of view of their efficiency, select and evaluate business strategies, compare heterogeneous systems, assess concepts and identify secondary problems as well as analyse the lifespan of the device. Thanks to its unique nature and scale, Si use allows several parameters to be analysed at the same time, as confirmed by the case of EM1 and EM2 protection half-masks.

\section{Acknowledgment}

This work is supported by the Ministry of Education, Science and Technological Development of the Government of the Republic of Serbia, within the framework of the TR34034 project.

\section{REFERENCES}

[1] D.Rajić (2017) Inventologija, Autorsko izdanje, Beograd.

[2] D.Rajić (2019) Eko-inventologija, Autorsko izdanje, Beograd.

[3] D.Rajić, Ž.Kamberović, B.Žakula (2016) Kreativni inženjering, IC TMF, Beograd.

[4] D.Rajić (2016) Kreativna ekologija, Autorsko izdanje, Beograd.

[5] D.Rajic (2018) Eco-innovative matrix based on TRIZ standards, MEFkon, Innovation as an initiator of the development "Innovations - basis for development", International Thematic Monograph - Thematic Proceedings, December 6th, University Business Academy in Novi Sad, Faculty of Applied Management, Economy and Finance, Belgrade, p. 154-171.

[6] A. Lyubomirskiy (2013) Ideality Equation, TRIZfest2013 International Conference, Kiev, Ukraine, proceedings, p. 16-25.

[7] J. Morones, J. Elechiguerra, A.Camacho, K.Holt, J. Kouri, J.Ramirez, M.Yacaman (2005) The bactericidal effect of silver nanoparticles, Nanotechnology, 16, 2346-2353.

[8] Y.Li, P.Leung, L.Yao, Q.Song, E.Newton (2006) Antimicrobial effect of surgical masks coated with nanoparticles, Journal of Hospital Infection, 62, 5863.

[9] B.Gutarowska, A.Michalski (2009) Antimicrobial activity of filtrating meltblow nonwoven with the addition of silver ions, FIBRES\&TEXTILES in Eastern Europe, 17(3), 23-28.

[10] SRPS EN 143:2007, Respiratory Protective Devices - Particle filters - Requirements, testing, marking, Institute for Standardization of Serbia.

[11] SRPS EN 149:2007, Respiratory Protective Devices - Filtering half masks to protect against particles - Requirements, testing, marking, Institute for Standardization of Serbia.

[12] N.Ivankovic, D.Rajic, M.llic, M.Vitorovic-Todorovic, N.Pajic (2012) Testing of the efficiency of military devices for personal respiratory protection in relation to sub-micron particles of biological agents, Digest Journal of Nanomaterials and Biostructures, 7(3), 1089-1095.

[13] N.Ivanković, D.Rajić, R.Karkalić, Z.Veličković, D. Jovanović, D.Inđić, M.Bučko (2017) Ispitivanje efikasnosti zaštite filtrirajućih polumaski pri različitim protocima aerosolnih kontaminanata, Zaštita materijala, 58(1), 17-21.

[14] Ю.Саламатов (1996) Система законов развития техники (основы теории развития технических систем), издание 2-е исправленное и дополненное, Institute of innovative design, Красноярск. 


\section{IZVOD}

\section{DOPRINOS IMPREGNISANIH NANOČESTICA SREBRA PORASTU IDEALNOSTI FILTRIRAJUĆIH SREDSTAVA RESPIRATORNE ZAŠTITE}

Tehnička kontradikcija se javlja kad se u sistemu poboljša jedan parametar, koji automatski prouzrokuje pogoršanje nekog njegovog drugog parametra. U takvoj situaciji, umesto uobičajenog prihvatanja kompromisa koji vodi ka optimizaciji rešenja nastalog problema, u inventologiji se sprovodi proces idealizacije. Eksperimentalni deo rada je obuhvatao komparativno ispitivanje propuštanja aerosola $\mathrm{NaCl}$, kao simulatora bioloških agenasa, prema unutrašnjosti epidemiološke maske antimikrobne EM1 i EM2. U cilju utvrdivanja fiziološke podobnosti EM1 i EM2, mereni su otpori koji nastaju pri udisanju aerosola $\mathrm{NaCl}$ kod protoka od $95 \mathrm{dm}^{3 /} \mathrm{min}$. Eksperimentalno je dokazano da impregnacija nanočestica srebra na unutrašnji filtrirajući sloj kod EM2 doprinosi porastu njegove efikasnosti, a matematičkim modelovanjem izračunat je realan porast idealnosti ovog sredstva.

Ključne reči: filtrirajuća polumaska, respiratorna zaštita, biološki aerosoli.

Naučni rad

Rad primljen: 29. 05. 2019.

Rad prihvaćen: 25. 07. 2019.

Rad je dostupan na sajtu: www.idk.org.rs/casopis

(c) 2019 Authors. Published by Engineering Society for Corrosion. This article is an open access article distributed under the terms and conditions of the Creative Commons Attribution 4.0 International license (https://creativecommons.org/licenses/by/4.0/) 